\title{
Study of weight variation and dissolution of Edoxaban split tablets in pharmacy practice
}

\author{
Mantiwee Nimworapan ${ }^{1 *}$, Sinwisuth Sutheechai ${ }^{1}$, Wanwarang Wongcharoen², Arintaya Phrommintikul2, \\ Suntara Eakanunkul ${ }^{3}$ \\ Department of Pharmaceutical care, Faculty of Pharmacy, Chiang Mai University, Chiang Mai, Thailand \\ 2 Division of Cardiology, Department of Internal Medicine, Faculty of Medicine, Chiang Mai University, Chiang Mai, Thailand \\ 3 Department of Pharmaceutical Sciences, Faculty of Pharmacy, Chiang Mai University, Chiang Mai, Thailand
}

\begin{abstract}
Edoxaban is available in $60 \mathrm{mg}, 30 \mathrm{mg}$, and $15 \mathrm{mg}$ unscored film-coated tablets. Tablet splitting may be an option to reduce medication costs and reduce the country's budget. The objectives of this study were to determine the weight variation and the dissolution profile of the $60 \mathrm{mg}$ edoxaban in split half-tablets using a pill splitter. Thirty edoxaban $60 \mathrm{mg}$ tablets were cut into halves by a right-handed pharmacist. The weight variation of the whole and half tablets were compared. For the dissolution test, 6 whole tablets and 12 half-tablets were separately dissolved in three dissolution media. Sixty half-tablets of edoxaban had the expected half-tablet weight within the $75 \%$ to $125 \%$ range that fell within the proxy United States Pharmacopeia (USP). The mean total weight of the $1^{\text {st }}$ and $2^{\text {nd }}$ halves were not significantly different from the mean weight of the intact tablets $(p$ value $=0.216$ ). The amount of drug release from the whole and half tablets in $0.1 \mathrm{~N} \mathrm{HCl}$ medium was greater than $85 \%$ in 15 minutes which met the acceptance criteria for the dissolution test. Edoxaban tablets splitting had low variations in weight. Therefore, edoxaban tablets can be split into halves by a tablet cutter.
\end{abstract}

Keywords:

Tablet splitting, Edoxaban, Weight variation, Dissolution test

\section{INTRODUCTION}

The practice of tablet splitting is common in clinical settings for dose reduction and cost savings ${ }^{1-2}$. Tablet splitting can have an economic incentive because of the parity pricing that uses flat rates for medications independent of dose strength. Therefore, splitting tablets can decrease the cost per dose and the estimated annual acquisition cost by $40 \%$ to $50 \%^{3-4}$. However, tablet splitting may result in fluctuation of the administration dose due to uneven halves, which can be clinically significant, especially for drugs with narrow therapeutic index. Scored or unscored tablets can be split into halves by hand, a knife, or a tablet cutter. Tablet splitting by hand can result in an inaccurate dose, therefore it is recommended to use a tablet splitter if possible ${ }^{5}$.

Edoxaban is a non-vitamin $\mathrm{K}$ antagonist oral anticoagulants (NOACs) or direct oral anticoagulants
(DOACs) that was approved in Japan in 2011, in the United States by the Food and Drug Administration (FDA) in January 2015, in the European Union in June 2015, and by the Thai FDA in December 2016 for stroke and systemic embolism risk reduction in nonvalvular atrial fibrillation (NVAF), treatment of deep vein thrombosis (DVT), and pulmonary embolism (PE) ${ }^{6-10}$. Dosage form and strengths of edoxaban are available in $60 \mathrm{mg}, 30 \mathrm{mg}$, and $15 \mathrm{mg}$ unscored film-coated tablets. The recommended dose is $60 \mathrm{mg}$ once daily, however, the dose should be reduced to $30 \mathrm{mg}$ once daily for patients with creatinine clearance $(\mathrm{CrCL}) 15-50 \mathrm{~mL} / \mathrm{min}$, have body weight less than or equal to $60 \mathrm{~kg}$ or those who use certain P-glycoprotein inhibitors ${ }^{10}$.

Edoxaban $60 \mathrm{mg}$ tablets used in this study do not have instructions about tablet splitting in the full prescribing information or leaflet. However, edoxaban tablets can be crushed and mixed with water or apple-

\section{*Corresponding author:}

*Mantiwee Nimworapan Email: mantiwee.nim@cmu.ac.th 
sauce and immediately administered by mouth or through a gastric tube ${ }^{10}$. To ensure that the split tablet contains the active drug within a range of label claim for patients to take a precise medication dose, the uniformity of dosage units of edoxaban half-tablet should be evaluated by measuring the content uniformity or weight variation. Film-coated tablets of edoxaban $60 \mathrm{mg}$ contain the drug substance of more than $25 \mathrm{mg}$, which meets the requirement for the weight variation test.

The objectives of this study were to investigate the differences in the weight variation and the dissolution profile of edoxaban split tablets using a tablet cutter.

\section{MATERIALS AND METHODS}

The edoxaban $60 \mathrm{mg}$ unscored tablets (Lixiana ${ }^{\circledR} 60 \mathrm{mg}$, Lot \#274567; Daiichi Sankyo Ltd, Japan) were used in the study (Figure 1). Edoxaban is an immediate release, film-coated tablet ${ }^{11}$. Each $60 \mathrm{mg}$ tablet contains $80.82 \mathrm{mg}$ edoxaban tosylate monohydrate equivalent to $60 \mathrm{mg}$ of edoxaban.

A tablet cutter (EZY dose one pill cutter) was purchased from a local community pharmacy. This tablet cutter consists of upper and lower platforms, which are connected by a hinge. The lower platform provides for the placement of the tablet within a V-shaped region. A razor blade is centered on the upper platform. A tablet is split by pressing the upper platform onto the lower platform (Figure 2).

\subsection{Tablet Characteristics: Dimension and Weight of Intact and Split Edoxaban Tablets}

The criteria used in the study were adapted from the United States Pharmacopoeia (USP) 43 chapter $<905>$ uniformity of dosage units test for whole tablets ${ }^{12}$ and chapter <705> quality attributes of tablets labeled as having a functional score $^{13}$. The diameter and thickness of the edoxaban $60 \mathrm{mg}$ tablet were measured using a vernier caliper. Thirty whole tablets of edoxaban were randomly weighed individually using a sensitive analytical balance (Sartorius, LA230S, Germany) with readability as low as $0.1 \mathrm{mg}$. The same weighed tablets were each cut into halves ( $1^{\text {st }}$ half and $2^{\text {nd }}$ half) by a tablet cutter and this was done by a right-handed pharmacist. Each half-tablet was weighed using the same analytical balance. The average weight, standard deviation (SD), relative standard deviation (\% RSD), percentage of expected half-tablet weight and percentage of weight loss were calculated. The USP guidance for quality attributes of splitting tablets with functional scoring test was applied for unscored edoxaban tablets ${ }^{13}$. As to the acceptance criteria, the measured half-tablet weight should be within the $75 \%$ to $125 \%$ range of the expected half-tablet weight and at least the weights of 56 half-tablets out of 60 half-tablets should be within the acceptance criteria ${ }^{13}$. Comparisons were made between the weight of the intact tablets and the corresponding total weight of the split tablets (paired t-test, $p$ value $=0.05$ ) to determine whether the splitting resulted in any significant loss of tablet mass.

The following parameters were assessed for weight variation of edoxaban tablets before and after splitting:

1. The expected half-tablet weight was calculated as whole tablet weight divided by 2 .

2. The percentage of the expected half-tablet weight was calculated by equation (1) as:

$$
\underline{\text { measured weight of each half-tablet }} \times 100
$$

(whole tablet weight $\div 2$ )

3 . The percentage of weight loss caused by the splitting process was calculated by equation (2) as:

weight of whole tablet-weight of $1^{\text {st }}$ and $2^{\text {nd }}$ half-tablets $\times 100$ weight of whole tablet

\subsection{Dissolution Study ${ }^{14}$}

The dissolution test of the whole and half tablets was performed with apparatus $2^{11}$ (paddle apparatus, Hanson Research, SR8 plus, United States) in 900 $\mathrm{mL}$ of three dissolution media: $0.1 \mathrm{~N} \mathrm{HCl}$, acetate buffer $\mathrm{pH} 4.5+0.2 \%$ sodium lauryl sulfate (SLS), and acetate buffer $\mathrm{pH} 4.5$ at $37 \pm 0.5$ Celsius and $50 \mathrm{rpm}$. The 6 whole tablets and 12 half-tablets were dissolved separately in each dissolution medium. A sample $(10 \mathrm{~mL})$ of the solution was withdrawn from the dissolution apparatus at 5, 10, 15, 30, 45, and $60 \mathrm{~min}$. Each aliquot was replaced with fresh dissolution medium at the same temperature except for the final measurement. Each aliquot was filtered and diluted to a suitable concentration with the dissolution medium. The absorbance of these solutions was measured at the maximum absorbance wavelength at $290 \mathrm{~nm}\left(\lambda_{\max }\right)$ of edoxaban using the ultraviolet (UV) spectrophotometer ${ }^{15}$ (Shimadzu, UV2450, Japan). Dissolution profiles of the whole tablets and half-tablets were created from the percentage of drug release into the media at each time point. The amount of dissolved active ingredient (Q) in the S1 stage dissolution test should not be less than $\mathrm{Q}+5 \%{ }^{14}$. In the $\mathrm{S} 2$ stage, the average of 12 units $(\mathrm{S} 1+\mathrm{S} 2)$ should be equal or greater than $\mathrm{Q}$, and no unit is less than $\mathrm{Q}-15 \%{ }^{14}$. The Q shown in the certificate of analysis of $60 \mathrm{mg}$ edoxaban tablets batch \#266202 is $75 \%$ within 30 minutes of the dissolution test.

The drug releases were calculated using the relative average absorbance of drug dissolved at time $t$ and $100 \%$ of drug dissolved as shown in equation (3):

[Absorbance ${ }_{t} \times$ Absorbance $_{100 \%}$ ] $\times 100$

The similarity factor $\left(f_{2}\right)$ for the intact-tablet results and the split-tablet portion results were calculated as shown in equation (4):

$$
f_{2}=50 \times \log \left\{\left[1+(1 / n) \sum_{t=1}^{n}\left(\mathrm{R}_{\mathrm{t}}-\mathrm{T}_{\mathrm{t}}\right)^{2}\right]^{-0.5} \times 100\right\}
$$


$\mathrm{R}_{\mathrm{t}}=$ cumulative percentage of the labeled drug dissolved at each of the selected $n$ time points of the intact tablets

$\mathrm{T}_{\mathrm{t}}=$ cumulative percentage of the labeled drug dissolved at each of the selected $\mathrm{n}$ time points of the split tablet portions
The calculated $f_{2}$ should not be less than 50 . The acceptable criteria for the similarity factor should be in the range of 50 to 100 according to USP 43 chapter $\langle 705\rangle^{13}$.

SPSS version 17.0 and Microsoft Excel (Microsoft Office 2019) were used for descriptive and

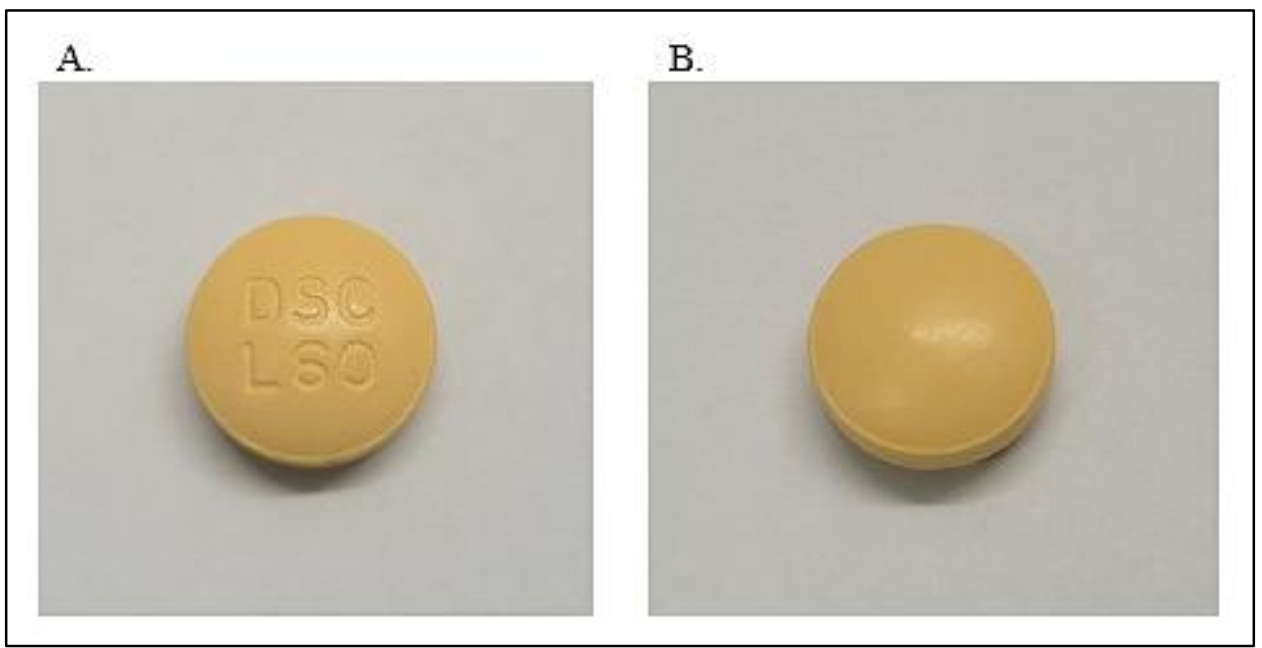

Figure 1. Edoxaban $60 \mathrm{mg}$ tablet: Front side (A), Back side (B).

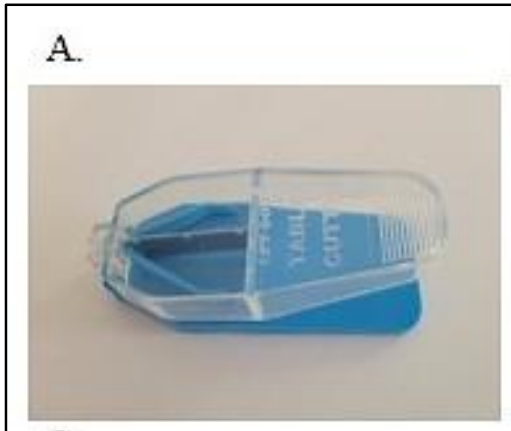

C.

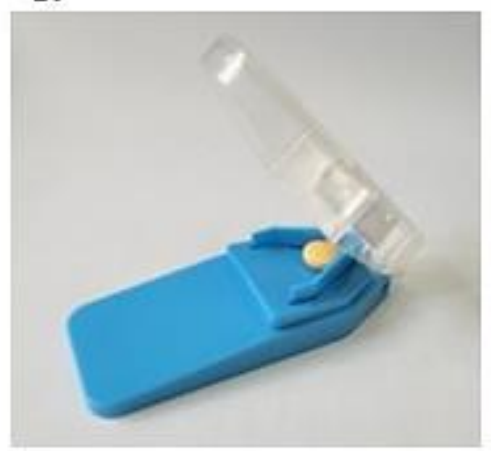

E.

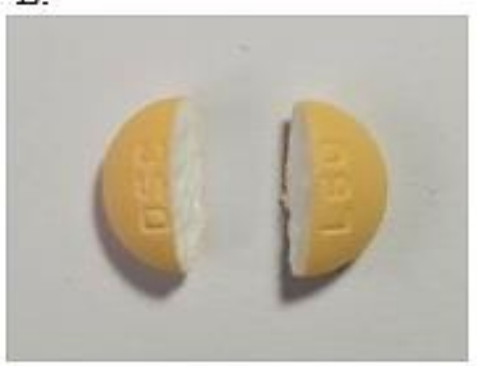

B.

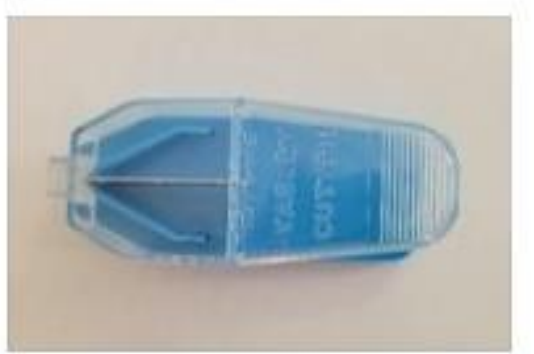

D.

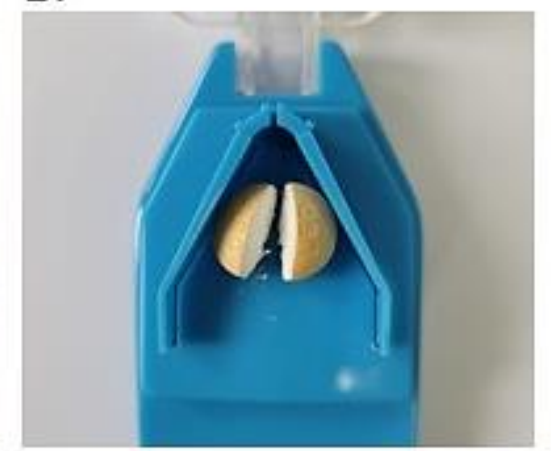

F.

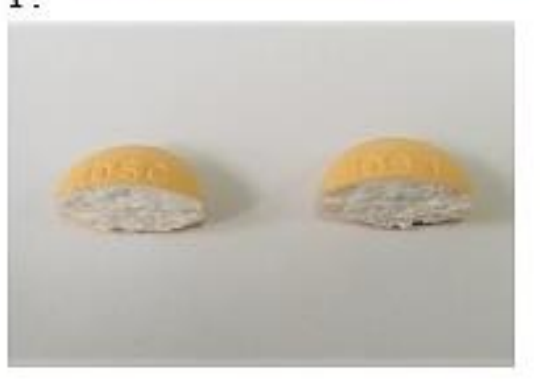

Figure 2. Tablet cutter (A): Top view of tablet cutter (B), Edoxaban $60 \mathrm{mg}$ tablet in a tablet cutter before splitting (C), Edoxaban tablet after splitting with a tablet cutter (D), Top view of split tablet portions (E), Side view of split tablet portions (F). 
Table 1. Weight Variation of Edoxaban Tablets Before and After Splitting ( $\mathrm{n}=30)$.

\begin{tabular}{|c|c|c|c|c|c|c|}
\hline No. & $\begin{array}{c}\text { Weight of Tablet } \\
\text { (g) }\end{array}$ & $\begin{array}{l}\text { Expected Weight } \\
\text { of Half Tablet (g) }\end{array}$ & $\begin{array}{l}\text { Weight of } 1^{\text {st }} \text { Half } \\
(\mathrm{g})\end{array}$ & $\begin{array}{c}\text { \%Expected } \\
{\text { Weight } 1^{\text {st }} \text { Half }}^{\text {\% }}\end{array}$ & $\begin{array}{l}\text { Weight of } 2^{\text {nd }} \\
\text { Half }(\mathrm{g})\end{array}$ & $\begin{array}{c}\text { \%Expected } \\
\text { Weight } 2^{\text {nd }} \text { Half }\end{array}$ \\
\hline 1 & 0.4384 & 0.2192 & 0.2230 & 101.7 & 0.2153 & 98.2 \\
\hline 2 & 0.4325 & 0.2163 & 0.2250 & 104.0 & 0.2068 & 95.6 \\
\hline 3 & 0.4345 & 0.2173 & 0.1962 & 90.3 & 0.2375 & 109.3 \\
\hline 4 & 0.4332 & 0.2166 & 0.2225 & 102.7 & 0.2101 & 97.0 \\
\hline 5 & 0.4375 & 0.2188 & 0.2205 & 100.8 & 0.2163 & 98.9 \\
\hline 6 & 0.4322 & 0.2161 & 0.2195 & 101.6 & 0.2125 & 98.3 \\
\hline 7 & 0.4306 & 0.2153 & 0.2217 & 103.0 & 0.2084 & 96.8 \\
\hline 8 & 0.4276 & 0.2138 & 0.2140 & 100.1 & 0.2126 & 99.4 \\
\hline 9 & 0.4274 & 0.2137 & 0.2350 & 110.0 & 0.1912 & 89.5 \\
\hline 10 & 0.4368 & 0.2184 & 0.2126 & 97.3 & 0.2233 & 102.2 \\
\hline 11 & 0.4356 & 0.2178 & 0.2171 & 99.7 & 0.2162 & 99.3 \\
\hline 12 & 0.4318 & 0.2159 & 0.2012 & 93.2 & 0.2295 & 106.3 \\
\hline 13 & 0.4318 & 0.2159 & 0.2335 & 108.2 & 0.1975 & 91.5 \\
\hline 14 & 0.4377 & 0.2189 & 0.2330 & 106.5 & 0.2037 & 93.1 \\
\hline 15 & 0.4234 & 0.2117 & 0.2227 & 105.2 & 0.2002 & 94.6 \\
\hline 16 & 0.4397 & 0.2199 & 0.2091 & 95.1 & 0.2296 & 104.4 \\
\hline 17 & 0.4335 & 0.2168 & 0.1925 & 88.8 & 0.2400 & 110.7 \\
\hline 18 & 0.4375 & 0.2188 & 0.2452 & 112.1 & 0.1915 & 87.5 \\
\hline 19 & 0.4332 & 0.2166 & 0.2122 & 98.0 & 0.2208 & 101.9 \\
\hline 20 & 0.4352 & 0.2176 & 0.2141 & 98.4 & 0.2208 & 101.5 \\
\hline 21 & 0.4221 & 0.2111 & 0.2268 & 107.5 & 0.1951 & 92.4 \\
\hline 22 & 0.4337 & 0.2169 & 0.1987 & 91.6 & 0.2347 & 108.2 \\
\hline 23 & 0.4299 & 0.2150 & 0.2176 & 101.2 & 0.2124 & 98.8 \\
\hline 24 & 0.4297 & 0.2149 & 0.2259 & 105.1 & 0.2034 & 94.7 \\
\hline 25 & 0.4315 & 0.2158 & 0.2245 & 104.1 & 0.2067 & 95.8 \\
\hline 26 & 0.4272 & 0.2136 & 0.2249 & 105.3 & 0.2023 & 94.7 \\
\hline 27 & 0.4332 & 0.2166 & 0.2238 & 103.3 & 0.2096 & 96.8 \\
\hline 28 & 0.4338 & 0.2169 & 0.2171 & 100.1 & 0.2167 & 99.9 \\
\hline 29 & 0.4299 & 0.2150 & 0.2130 & 99.1 & 0.2165 & 100.7 \\
\hline 30 & 0.4338 & 0.2169 & 0.2190 & 101.0 & 0.2148 & 99.0 \\
\hline
\end{tabular}

Table 2. Weight Results for Edoxaban Tablets Before and After Splitting ( $n=30)$.

\begin{tabular}{lcccccc}
\hline Analysis & Whole Tablets & $\begin{array}{c}\text { Sum of the Two } \\
\text { Halves }\end{array}$ & \% Weight Loss & $\mathbf{1}^{\text {st }}$ Half-Tablets & $\begin{array}{c}\mathbf{2}^{\text {nd }} \text { Half- } \\
\text { Tablets }\end{array}$ & $\begin{array}{c}P \text {-value } \\
\text { (paired t-test) }\end{array}$ \\
\hline Mean (g) & 0.4325 & 0.4319 & 0.1308 & 0.2187 & 0.2132 & 0.216 \\
SD & 0.0042 & 0.0041 & 0.1182 & 0.0115 & 0.0127 & - \\
RSD (\%) & 0.9663 & 0.9488 & - & 5.2754 & 5.9746 & - \\
SEM & 0.0008 & 0.0007 & 0.0216 & 0.0021 & 0.0023 & - \\
\hline
\end{tabular}

$\mathrm{RSD}=$ relative standard deviation, $\mathrm{SD}=$ standard deviation, $\mathrm{SEM}=$ standard error of mean

analytical statistics. Two-sided t-test analysis was used assuming $p<0.05$ for inferential statistical analysis.

\section{RESULTS}

\subsection{Tablet Characteristics: Dimension and Weight of Intact and Split Edoxaban Tablets}

The size of an edoxaban $60 \mathrm{mg}$ tablet measured with a vernier caliper is $10.8 \mathrm{~mm}$ in diameter and 5.5 $\mathrm{mm}$ in thickness. All 60 half-tablets of edoxaban had the expected half-tablet weight within the $87.5 \%$ to $112.1 \%$ range that fell within the proxy USP 43 chapter $\langle 705\rangle{ }^{13}$ (Table 1).

Edoxaban split tablets had low variation in weight with \%RSD values less than 6\% (proxy USP specification for $\%$ RSD) ${ }^{11}$ and mean percent weight loss of $0.13 \%$ (Table 2 ). The mean total weight of the $1^{\text {st }}$ and $2^{\text {nd }}$ halves were not significantly different from the mean weight of the intact tablets $(p$-value $=0.216)$ as indicated by paired t-test analysis (Table 2). Edoxaban split tablets using a tablet cutter had a smooth cut as shown in Figure 2.

\subsection{Dissolution Study}

The UV absorption spectrum was obtained for edoxaban identification (Figure 3 ). The edoxaban spectrum showed maximum absorption wavelength $\left(\lambda_{\max }\right)$ at $290 \mathrm{~nm}$ where the absorbance of edoxaban solution was measured at different time points.

The dissolution results for the whole and half tablets of edoxaban in $0.1 \mathrm{~N} \mathrm{HCl}$ medium are shown in Figure 4. The dissolution for the whole and half tablets occurred within 10-15 minutes and 7-10 minutes, respectively. The maximum of drug release from the whole and half tablets occurred at 20 minutes and 15 minutes, 


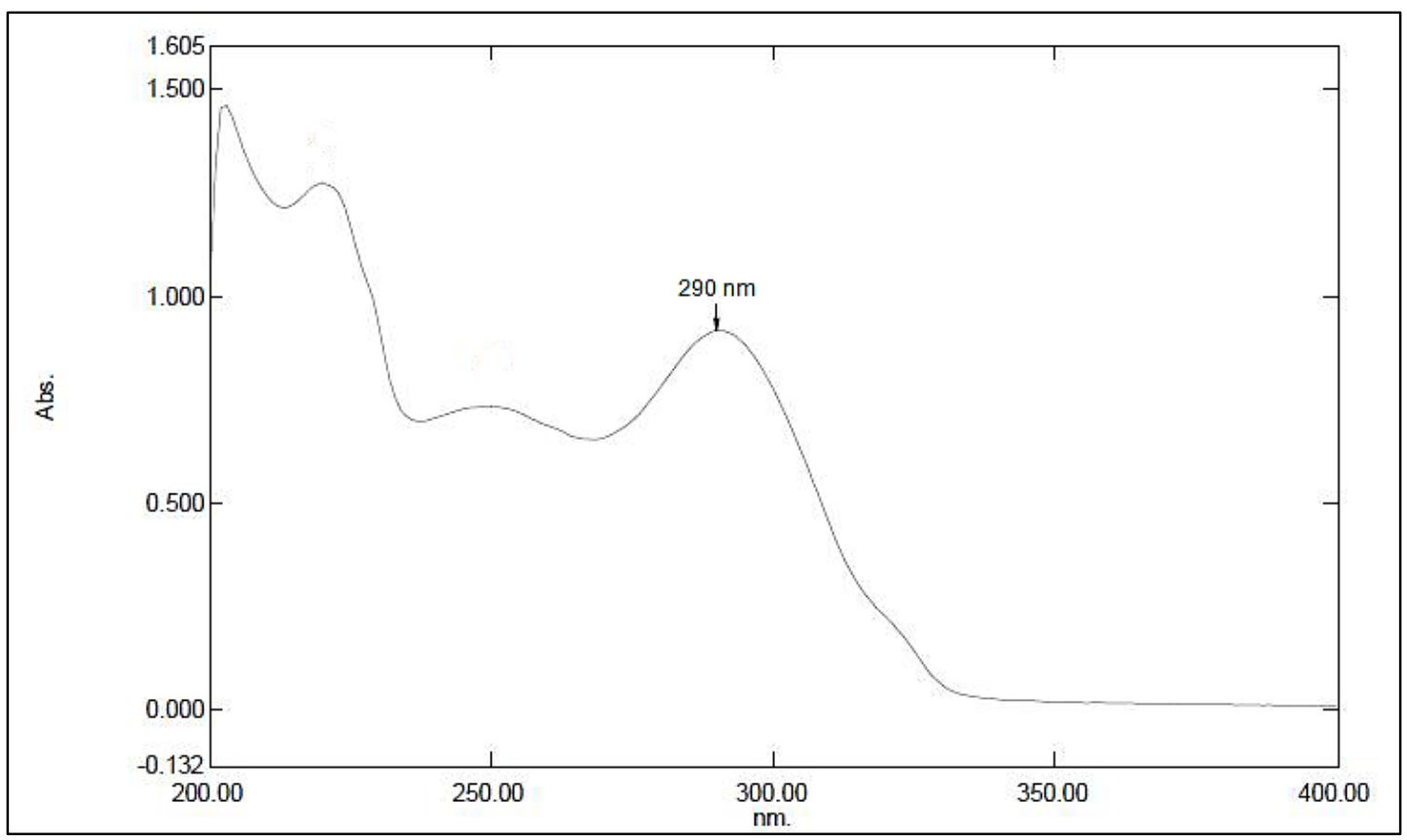

Figure 3. The maximum absorbance wavelength $\left(\lambda_{\max }\right)$ of edoxaban at $290 \mathrm{~nm}$.

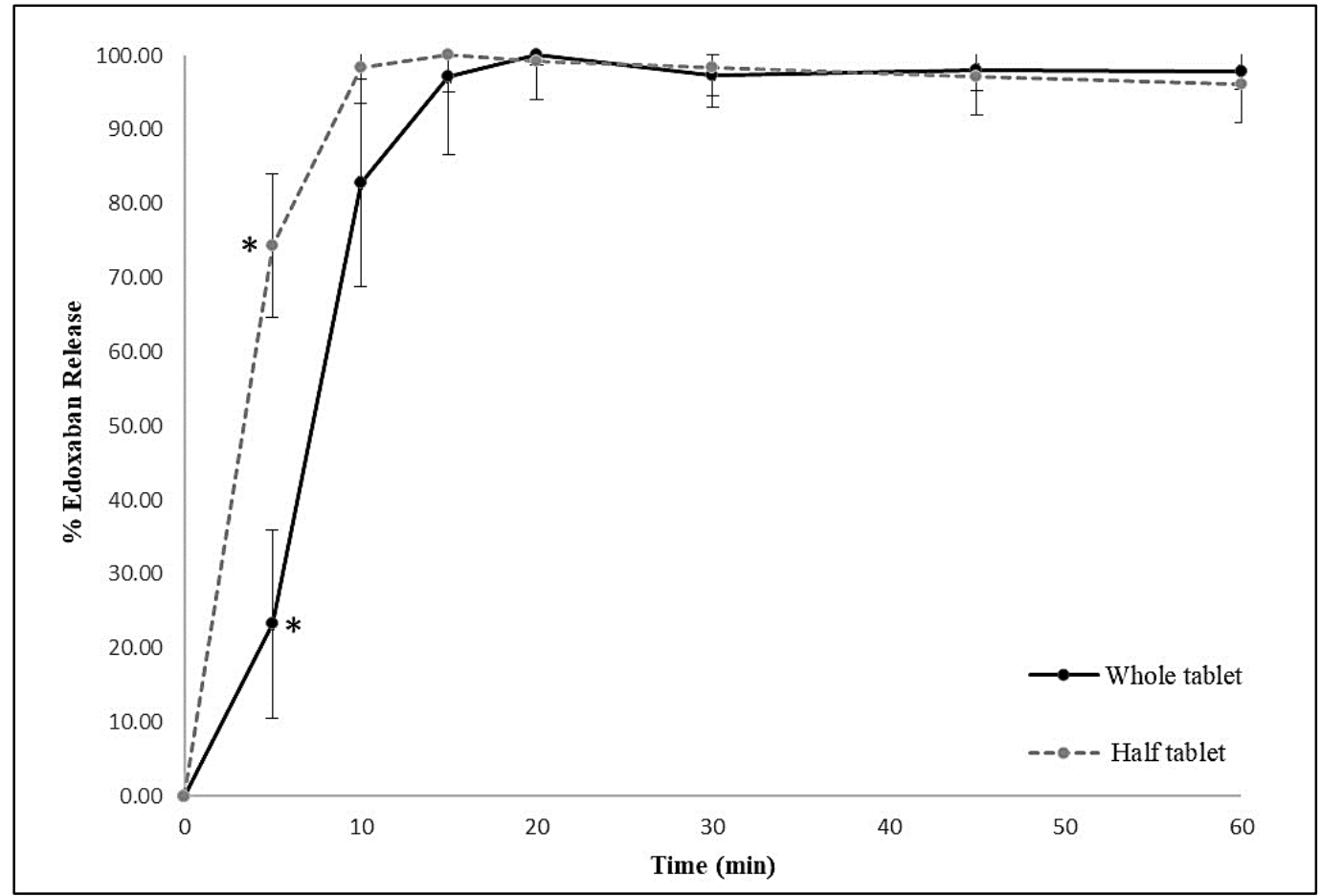

Figure 4. Dissolution profiles of the edoxaban whole tablets $(\mathrm{n}=6)$ and half-tablets $(\mathrm{n}=12)$ in $0.1 \mathrm{~N} \mathrm{HCl}$ medium. $(* p<0.05$ at 5 minutes)

Table 3. Percentage of Drug Release of the Whole and Half Edoxaban Tablets in $0.1 \mathrm{~N} \mathrm{HCl} \mathrm{Medium.}$

\begin{tabular}{ccrrc}
\hline Time (min) & \%Drug Release of Whole Tablets & SD & \%Drug Release of Half Tablets & SD \\
\hline 0 & 0.00 & 0.00 & 0.00 & 0.00 \\
5 & 23.25 & 12.75 & 74.29 & 9.65 \\
10 & 82.81 & 13.94 & 98.38 & 4.89 \\
15 & 97.07 & 10.48 & 100.00 & 5.02 \\
20 & 100.00 & 1.26 & 99.21 & 5.18 \\
30 & 97.35 & 2.77 & 98.32 & 5.30 \\
45 & 98.00 & 2.81 & 97.17 & 5.14 \\
60 & 97.87 & 2.37 & 96.09 & \\
\hline
\end{tabular}

$\mathrm{SD}=$ standard deviation 


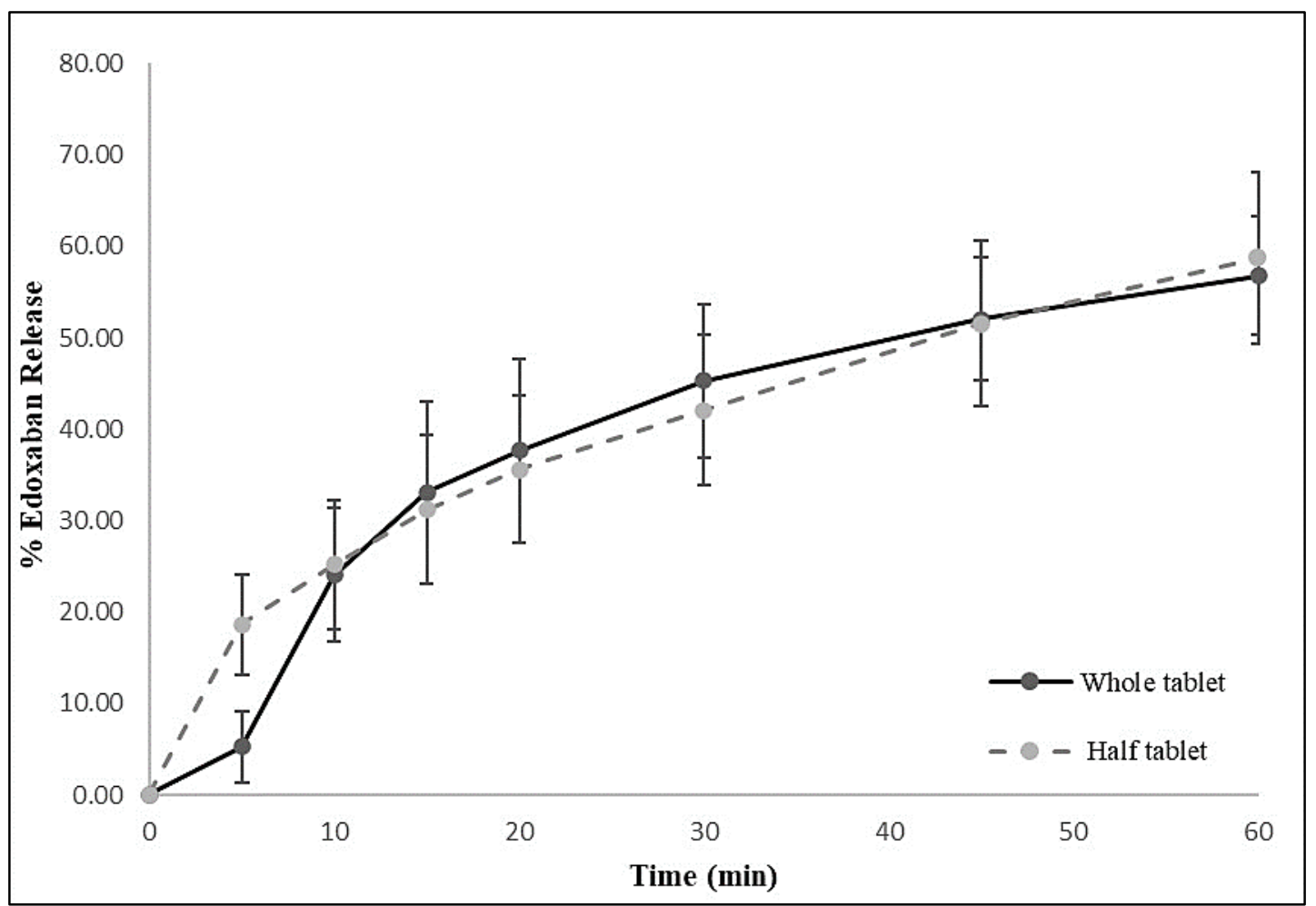

Figure 5. Dissolution profiles of the edoxaban whole tablets $(n=6)$ and half-tablets $(n=12)$ in acetate buffer pH $4.5+0.2 \%$ sodium lauryl sulfate (SLS) medium.

Table 4. Percentage of Drug Release of the Whole and Half Edoxaban Tablets in Acetate Buffer pH 4.5+0.2\% SLS Medium.

\begin{tabular}{ccccc}
\hline Time (min) & \%Drug Release of Whole Tablets & SD & \%Drug Release of Half Tablets & SD \\
\hline 0 & 0.00 & 0.00 & 0.00 & 0.00 \\
5 & 5.25 & 3.90 & 18.65 & 5.50 \\
10 & 24.07 & 7.31 & 25.20 & 7.03 \\
15 & 33.07 & 9.96 & 31.23 & 8.09 \\
20 & 37.69 & 10.04 & 35.57 & 8.04 \\
30 & 45.28 & 8.45 & 42.09 & 9.18 \\
45 & 52.05 & 6.77 & 51.50 & 9.40 \\
60 & 56.77 & 6.49 & 58.75 & \\
\hline
\end{tabular}

$\mathrm{SD}=$ standard deviation

respectively (Table 3).

The amounts of drug release from the whole and half tablets were greater than $85 \%$ in 15 minutes, which met the acceptance criteria of the dissolution test. The average of the drug release from 12 half-tablets in $0.1 \mathrm{~N} \mathrm{HCl}$ medium at 30 minutes met the acceptance criteria in the S1 and S2 stages of the dissolution test. The similarity factor for the whole and half tablets of edoxaban dissolution profile in $0.1 \mathrm{~N} \mathrm{HCl}$ medium was 34.7, which did not meet the acceptance criteria. However, dissolution profiles of whole and half tablets of edoxaban after 5 minutes were found to be similar in acidic condition (Figure 5). The half-tablets dissolved faster than the whole tablets with the statistically significant difference $(p$-value $<0.05)$ of cumulative drug release just within the first 5 minutes.

The dissolution results for the whole and half tablets of edoxaban in acetate buffer $\mathrm{pH} 4.5+0.2 \%$ SLS are shown in Figure 5. The similarity factor for the whole and half tablets of edoxaban dissolution profile was 63.1, which met the acceptance criteria. The drug release from 12 half-tablets in acetate buffer $\mathrm{pH} 4.5+0.2 \%$ SLS did not meet the acceptance criteria in the $\mathrm{S} 1$ and $\mathrm{S} 2$ stages of the dissolution test. At 60 minutes, the percentages of drug release of the whole and half tablets were less than $60 \%$ (Table 4).

The whole and half edoxaban tablets did not dissolve in acetate buffer $\mathrm{pH} 4.5$ alone medium within 60 minutes. Therefore, we decided not to measure the UV absorption spectrum of the sample solution in those media for the drug release calculation.

\section{DISCUSSION}

The weight variation of edoxaban $60 \mathrm{mg}$ halftablets using a tablet cutter indicates small loss of mass. Edoxaban half-tablets had weight variations that fell into the proxy USP specification ${ }^{13}$. There was no diffe- 
rence between mean weights of the two halves and intact tablets. Using a splitting device provided less weight loss compared with scissors for unscored tablets, hand splitting for scored tablets, or a kitchen knife ${ }^{16}$. Edoxaban unscored film-coated tablet has a biconvex face which is hard to split by hand. Therefore, splitting with a tablet splitter should be used for more consistency in half-tablet doses. Other characteristics, such as hardness, size, thickness, and shape of the tablets can also affect the accuracy and uniformity of tablet splitting ${ }^{17}$. Thus, the hardness of edoxaban tablet should be determined. Additionally, the friability of the intact and half tablets of edoxaban should be performed in further study.

Edoxaban has no published standard method of its analysis. Therefore, this study performed the dissolution test in the three-dissolution media to find the best condition for edoxaban drug release. The $\mathrm{Q}$ shown in a certificate of analysis of $60 \mathrm{mg}$ edoxaban tablets batch \#266202, which is $75 \%$ within 30 minutes of the dissolution test, has been used for the acceptance criteria of the dissolution test due to the unavailability of the official edoxaban monograph. Edoxaban oral bioavailability is approximately $62 \%$. Edoxaban can be administered with or without food because food does not affect total exposure to edoxaban ${ }^{10}$. Hence, we tested the dissolution of edoxaban in the media with $\mathrm{pH}$ of fasted (typically 1-2) and fed states (about 3-7) in the stomach and upper small intestine ${ }^{18}$. We chose the dissolution in $\mathrm{pH} 4.5$ acetate buffer (with or without SLS) for fed states, instead of medium with pH 6.8 due to the low solubility of edoxaban at $\mathrm{pH} 6-7^{10}$. The intact and half tablets of edoxaban dissolved well and passed the dissolution test in the acidic condition that simulated gastric fluid without enzymes in $0.1 \mathrm{~N} \mathrm{HCl}$ medium. The drug release rate or the dissolution rate of the split tablets was not different from that of the intact tablets. This finding is consistent with the pKa 6.7 of edoxaban, which means the drug can dissolve well in an acidic solution ${ }^{10}$. Additionally, edoxaban is absorbed mainly in the upper gastrointestinal tract ${ }^{8,19}$, which is in an acidic state. Edoxaban is less dissolved in neutral solution, and does not dissolve in basic solution with $\mathrm{pH}$ range of 8$9^{10}$. In this study, we found that the whole and half tablets of edoxaban did not dissolve well in $\mathrm{pH} 4.5$ acetate buffer (with or without SLS).

The similarity factor for the whole and half tablets of edoxaban dissolution profile in $0.1 \mathrm{~N} \mathrm{HCl}$ medium failed to meet the acceptance criteria. However, the t-test showed that the half-tablets dissolved faster than the whole tablets with the statistically significant difference ( $p$-value $<0.05$ ) of cumulative drug release just within the first 5 minutes. The damage of film-coated tablets resulting in the burst of drug release from halftablets would affect the larger extent of absorption and follow with the rapid onset of action. However, this might have a minimal effect on the clinical efficacy because edoxaban tablets can be crushed and given through a nasogastric tube that showed similar exposure compared to administration of an intact tablet ${ }^{10}$.

This study had some limitations that should be considered. First, the USP does not have tests for the weight variation or the content uniformity of the halftablet. Therefore, we used adapted USP criteria for assessing half-tablet weight variability as was done in previous studies ${ }^{17,20-22}$. Second, this study used the solution of the whole tablet of edoxaban in each dissolution medium as the reference in the dissolution test, because we were unable to find the edoxaban reference standard. Third, the test procedure of splitting tablets in this study mainly followed the USP 43 guidance chapter $\langle 705\rangle^{13}$; however, the edoxaban is an unscored tablet that cannot be split by hand. Therefore, this study can be applied only by using a tablet cutter for splitting technique; perhaps the other techniques such as splitting tablets with a kitchen knife or scissors would have shown different variability results. However, we recommend using a tablet cutter to improve the accuracy and uniformity of tablet splitting. Fourth, a single pharmacist performed all tablet splitting using a tablet cutter to eliminate the variables that might be introduced by multiple testers. Therefore, the tablet splitting technique in this study may not be representative of patients in the general population who may have difficulty splitting tablets, poor cognition or memory, or compromised physical dexterity. The pharmacist should instruct these patients and care givers in the accurate use of a tablet-splitting device. Lastly, this study did not measure the clinical outcomes of tablet splitting in patients. Therefore, the minor dose variation from a half-tablet of edoxaban may or may not have clinical impact outcomes or adverse effects.

\section{CONCLUSIONS}

Edoxaban tablets can be split into halves by a tablet cutter for dosage unavailability or for cost saving reasons. This conclusion is based on the half-tablets of edoxaban exhibiting low variation in weight compared to that of whole tablets. Additionally, dissolution profiles of whole and half-tablets of edoxaban were found to be similar. However, equal daily doses will be determined by the ability of patients to split tablets perfectly in half with a tablet cutter. Further study of clinical impact of use of edoxaban half-tablet should be performed.

\section{ACKNOWLEDGEMENT}

The authors wish to thank Dr. Darunee Hongwiset, Associate Professor Songwut Yotsawimonwat, Associate Professor Sirivipa Piyamongkol, and Dr. Pimchanok Charoongchit for comments and suggestions to the study. The skillful technical help from Narakorn 
Khamfoo is greatly appreciated.

\section{Conflict of interest}

The authors declare no potential conflict of interest with respect to the research, authorship, and/or publication of this article.

\section{Funding}

This study was funded by Faculty of Pharmacy, Chiang Mai University, Thailand.

\section{Ethics approval}

None to declare.

\section{Article info:}

Received July 18, 2021

Received in revised form November 9, 2021

Accepted November 14, 2021

\section{REFERENCES}

1. Quinzler R, Gasse C, Schneider A, Kaufmann-Kolle P, Szecsenyi J, Haefeli WE. The frequency of inappropriate tablet splitting in primary care. Eur J Clin Pharmacol. 2006;62(12):1065-73.

2. Stafford RS. Radley DC. The potential of pill splitting to achieve cost savings. Am J Manag Care. 2002;8(8):706-12.

3. Gee M, Hasson NK, Hahn T, Ryono R. Effects of a tablet-splitting program in patients taking HMG-CoA reductase inhibitors: analysis of clinical effects, patient satisfaction, compliance, and cost avoidance. J Manag Care Pharm. 2002;8(6):453-8.

4. Fawell NG, Cookson TL, Scranton SS. Relationship between tablet splitting and compliance, drug acquisition cost, and patient acceptance. Am J Health Syst Pharm. 1999;56(24):2542-5.

5. Fahelelbom KM, Al-Tabakha MM, Eissa NA, Javadi J. Evaluation of certain pharmaceutical quality attributes of lisinopril split tablets. Sci Pharm. 2016;84(4):646-53.

6. Daiichi Sankyo Launches LIXIANA(R) (edoxaban), a Direct Oral Factor Xa Inhibitor, in Japan for the Prevention of Venous Thromboembolism after Major Orthopedic Surgery [document on the Internet]. Japan: Daiichi Sankyo; 2011 [cited 2020 Nov 8]. Available from: https://www.daiichisankyo.com/media/press_ release/detail/index_3755.html.

7. Savaysa (edoxaban tosylate) tablets NDA 206316 approval letter [document on the Internet]. Silver Spring, MD: U.S. Food and Drug Administration; 2015 [cited 2020 Nov 8]. Available from: https://www.accessdata.fda.gov/drugsatfda_docs/nda/2015/206 316Orig1Orig2s000Approv.pdf.

8. Lixiana (edoxaban) [document on the Internet]. Netherlands: European Medicines Agency; 2015 [updated 2020 Sep 16; cited 2020 Nov 8]. Available from: https://www.ema.europa.eu/en/ medicines/human/EPAR/lixiana.

9. Lixiana $60 \mathrm{mg}$ (Details of Medicinal Product) [document on the Internet]. Nonthaburi: Food and Drug Administration, Ministry of Public Health; 2016 [updated 2019 Oct 3; cited 2020 Nov 8]. Available from: http://pertento.fda.moph.go.th/FDA_SEARCH_ DRUG/SEARCH_DRUG/pop-up_drug.aspx?Newcode_U=U1 DR1C1012590010611C.

10. Savaysa [Package insert]. Basking Ridge, NJ: Daiichi Sankyo, Inc.; 2020.

11. Savaysa (edoxaban tosylate) tablets NDA 206316 chemistry review [document on the Internet]. Silver Spring, MD: U.S. Food and Drug Administration; 2015 [cited 2021 Sep 8]. Available from: https://www.accessdata.fda.gov/drugsatfda_docs/nda/ 2015/206316Orig1Orig2s000ChemRedt.pdf.

12. The United States Pharmacopeia 43-National Formulary 38,
Vol. 4. Chapter 905 Uniformity of dosage units. Rockville (MD): United States Pharmacopeial Convention; 2020. p. 7183.

13. The United States Pharmacopeia 43-National Formulary 38, Vol. 4. Chapter 705 Quality attributes of tablets labeled as having a functional score. Rockville (MD): United States Pharmacopeial Convention; 2020. p. 6944.

14. United States Pharmacopeia 43-National Formulary 38, Vol. 4. Chapter 711 Dissolution. Rockville (MD): United States Pharmacopeial Convention; 2020. p. 6945.

15. Ravisankar P, Srikanth D, Reddy CV. Development and validation of UV spectrophotometric method for the determination of Edoxaban Tosylate Monohydrate in pharmaceutical dosage form. Ind J Res Phar Biotechnol. 2018;6(2):73-8.

16. Verrue C, Mehuys E, Boussery K, Remon JP, Petrovic M. Tablet-splitting: a common yet not so innocent practice. J Adv Nurs. 2011;67(1):26-32.

17. Helmy SA. Tablet splitting: Is it worthwhile? Analysis of drug content and weight uniformity for half tablets of 16 commonly used medications in the outpatient setting. J Manag Care Spec Pharm. 2015;21(1):76-86.

18. Mudie DM, Amidon GL, Amidon GE. Physiological parameters for oral delivery and In vitro testing. Mol Pharm. 2010;7(5): $1388-405$.

19. Parasrampuria DA, Truitt KE. Pharmacokinetics and pharmacodynamics of edoxaban, a non-vitamin $\mathrm{K}$ antagonist oral anticoagulant that inhibits clotting factor Xa. Clin Pharmacokinet. 2016;55:641-55.

20. Polli JE, Kim S, Martin BR. Weight uniformity of split tablets required by a Veterans Affairs policy. J Manag Care Pharm. 2003;9(5):401-7.

21. Hill SW, Varker AS, Karlage K, Myrdal PB. Analysis of drug content and weight uniformity for half tablets of 6 commonly split medications. J Manag Care Pharm. 2009;15(3):253-61.

22. Tahaineh LM, Gharaibeh SF. Tablet splitting and weight uniformity of half tablets of 4 medications in pharmacy practice. J Pharm Pract. 2012;25(4):471-6. 